\title{
Assessing the feasibility and quality of shared decision making in China: evaluating a clinical encounter intervention for Chinese patients
}

This article was published in the following Dove Press journal:

Patient Preference and Adherence

14 November 2016

Number of times this article has been viewed

\author{
Rongchong Huangl,* \\ Xiantao Song ${ }^{2, *}$ \\ Jian $\mathrm{Wu}^{\prime}$ \\ Wei Huang ${ }^{2}$ \\ Aaron L Leppin ${ }^{3}$ \\ Michael R Gionfriddo 3,4 \\ Yongxian Liu' \\ Kasey R Boehmer ${ }^{3}$ \\ Henry H Ting ${ }^{5}$ \\ Victor M Montori ${ }^{3,6}$ \\ 'Department of Cardiology, The First \\ Affiliated Hospital of Dalian Medical \\ University, Dalian, ${ }^{2}$ Department \\ of Cardiology, Beijing An Zhen \\ Hospital, Capital Medical University, \\ Beijing, People's Republic of China; \\ ${ }^{3}$ Knowledge and Evaluation Research \\ Unit, ${ }^{4}$ Mayo Graduate School, Mayo \\ Clinic, Rochester, MN, ${ }^{5}$ Value Institute, \\ New York-Presbyterian Hospital, The \\ University Hospital of Columbia and \\ Cornell, New York, NY, ' ${ }^{6}$ ivision of \\ Endocrinology, Mayo Clinic, Rochester, \\ MN, USA
}

*These authors contributed equally to this work
Background: The aim of this study was to evaluate the feasibility of using the Statin Choice decision aid to have discussions about starting a statin medication for cardiovascular risk reduction in Chinese patients with stable coronary artery diseases.

Methods: A prospective, pilot study of the Statin Choice decision aid in two teaching hospitals in Northern China was conducted. A total of seven clinicians were enrolled and underwent a 12-hour, group-based, in-person training on shared decision making (SDM) and the Statin Choice decision aid. Then, these clinicians used the Statin Choice decision aid in patients during a clinical encounter. A total of 86 patients aged 40-80 years, who had stable angina, were enrolled. All clinical encounters were video recorded. A team of three researchers viewed and scored all the encounter recordings to evaluate the SDM process and fidelity to the intervention using the OPTION scale and Fidelity scale, respectively. All the patients were followed up for 12 months to record adherence to statin and any major adverse cardiac events (MACEs).

Results: The average scores on the OPTION normalized score and Fidelity scale were 21 (range, 3-32; out of a possible, 48) and 10 (range, 6-10; out of a possible, 10), respectively. This suggested that Chinese clinicians who were using Statin Choice in their patients were able to exhibit behaviors consistent with SDM at a level that is similar to that reported in Western countries. After SDM, the statin adherence was $94.5 \%(69 / 73)$, and the proportion of MACEs was $2.9 \%(2 / 69)$.

Conclusion: Using an encounter decision aid developed in the US, it was feasible to implement SDM in a referral cardiology practice in Mainland China. Further work to ensure that the encounter aid is pertinent to the Chinese population and that SDM is tested in at-risk patients could contribute to the implementation of SDM across Mainland China.

Keywords: Statin Choice, decision aid, stable angina, statin adherence, shared decision making, China

\section{Introduction}

Shared decision making (SDM) is an essential process in evidence-based medicine ${ }^{1}$ and is considered the pinnacle of patient-centered care. ${ }^{2}$ This process involves patients and clinicians working together to determine, through collaborative deliberation ${ }^{3}$ and use of research evidence, which treatment option is best for each individual. SDM and interventions for its facilitation have been developed outside of the Chinese context, which casts uncertainty over the applicability of this evidence to the Chinese context.

Existing work on SDM in China has focused on attitudes toward and prevalence of the practice of $\mathrm{SDM}^{4}$ but has not evaluated the interventions to implement SDM. Research that seeks to better understand the applicability of SDM within the Chinese context is important
Correspondence: Rongchong Huang Department of Cardiology, The First Affiliated Hospital of Dalian Medical University, 222 Zhongshan Road, Xigang District, Dalian I I60 I I, People's Republic of China

Email rchuang@dlmedu.edu.cn 
and may improve the trust between patients and clinicians, ${ }^{5}$ which is an essential health care reform target in China.

In an earlier study, an SDM intervention - the Statin Choice decision aid ${ }^{6,7}$ - enhanced decision making about statin drugs and may have favorably affected medication adherence in patients with type 2 diabetes mellitus in the US. Our objective was to evaluate the feasibility of using the Statin Choice decision aid in China to help patients and clinicians have discussions about starting a statin medication for cardiovascular risk reduction. We sought to compare the outcomes from the use of Statin Choice decision aid to those previously reported in Western settings and to investigate Chinese clinicians' and patients' preferences regarding SDM after experiencing it. This study will inform future large-scale trials as well as begin to identify barriers and facilitators of SDM in the Chinese context.

\section{Research design and methods Methods \\ Study design and setting}

We conducted a prospective, feasibility study of an SDM intervention at two teaching hospitals in Northern China, between December 2013 and June 2014 (Figure 1). The ethics committee of the First Affiliated Hospital of Dalian Medical University approved this study. All patients provided written informed consent to be apart of the study.

\section{Study participants}

Eligible clinicians were cardiologists who were in clinical practice for at least 1 year. Eligible patients were between 40 years and 80 years of age, with stable angina, who were found to have coronary stenosis $>50 \%$ by angiogram according to the 2014 American College of Cardiology/American Heart Association guideline ${ }^{8}$ for the diagnosis and management of patients with stable ischemic heart disease. They also had no symptoms or no chest pain in the last week, no major barriers to providing written consent, and agreed to be followed up for 12 months. Patients were excluded if their life expectancy was $<12$ months and if they had drug allergies or contraindications to aspirin or statins. We delivered the SDM intervention (with the Statin Choice decision aid) prior to giving them statin.

\section{Clinician training}

Prior to patient enrollment, a study team member conducted a 12-hour, group-based, in-person training for clinicians, which focused on how to use the Statin Choice decision aid (Figure 2).

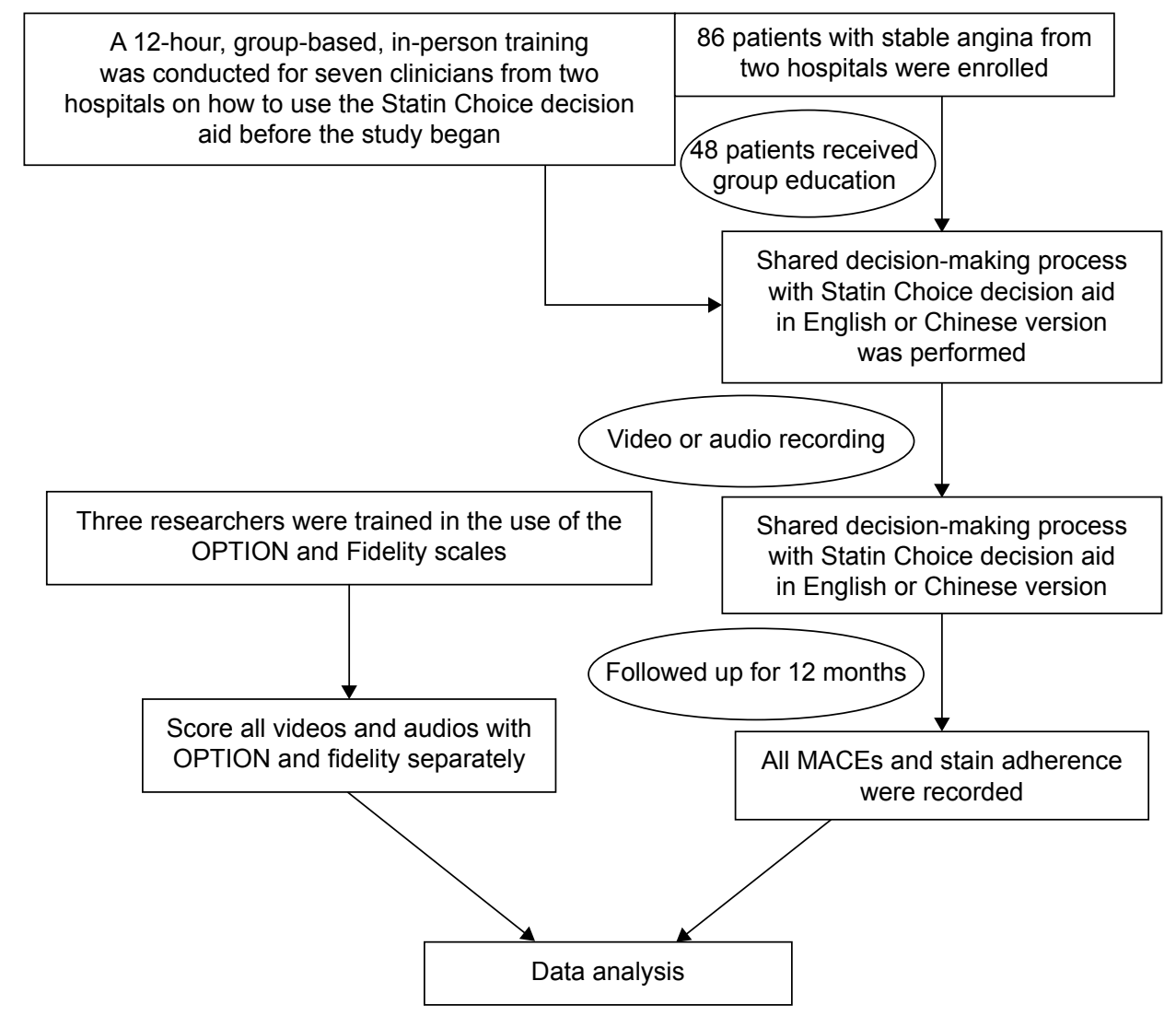

Figure I Flow diagram of the study protocol.

Abbreviation: MACEs, major adverse cardiac events. 


\section{THE STATIN CHOICE DECISION AID}

Prepared exclusively for

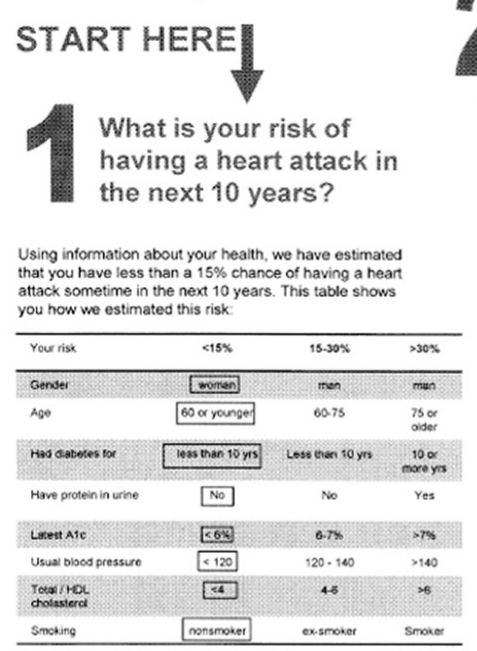

In addition, you are lowering your cardiovascular risk by regularty using a baby
[ramipril (Altace@))

What does this estimate mean? It means that out of 100 people like you, about 10 will not.

Keep in mind that we do not know what will happen to you, if you were to have a heart attack we cannot te
(1) What benefit can you expect from taking statins compared to not taking statins?

Here is your risk if you decide not to take statins
NO STATIN
Our guess of what will happen to 100
people like you if they were to decide
like to take statins: out of 100 people
lattack in the next 10 will have a heart
90 will not.

Here is your risk if you decide to take statins

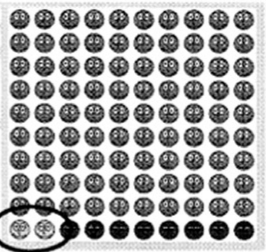

ATTENTION! If you were to decide to take statins, we will not know if you would be among those who would having a heart attack or by having one despite taking statins regularly) those who would benefit (by avading a heart attock

\section{YES STATIN}

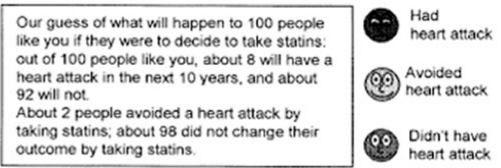

What downsides can you expect from taking statins compared to not taking statins?

1. What do you want to do now?

- Statins need to be taken daily for years.

- Some statins may cost less to you depending on your drug plan.

Take (or continue to take) statins

a Not take (or stop taking) statins

Common side effects: nausea, diarrhea, constipation imos patients can tolerate) Muscle aching/stiffness: 5 in 100 patients (some need to stop
statins because of this)

Liver enzymes go up (no pain, no permanent liver damage): 2 in 100 patients (some need to s:op statins because of this. Muscle and kidney damage: 1 in 20,000 patients (requires a Discuss with your clinician today

a Discuss with your clinician in the future When?

Discuss with others

Who?

O Nayo Foundation 2005. This intormation reflects the accuracy of your medical record and the best avalable research studies. It was prepared withoul tunding from makers of statins by Mayo Clinic researchers.

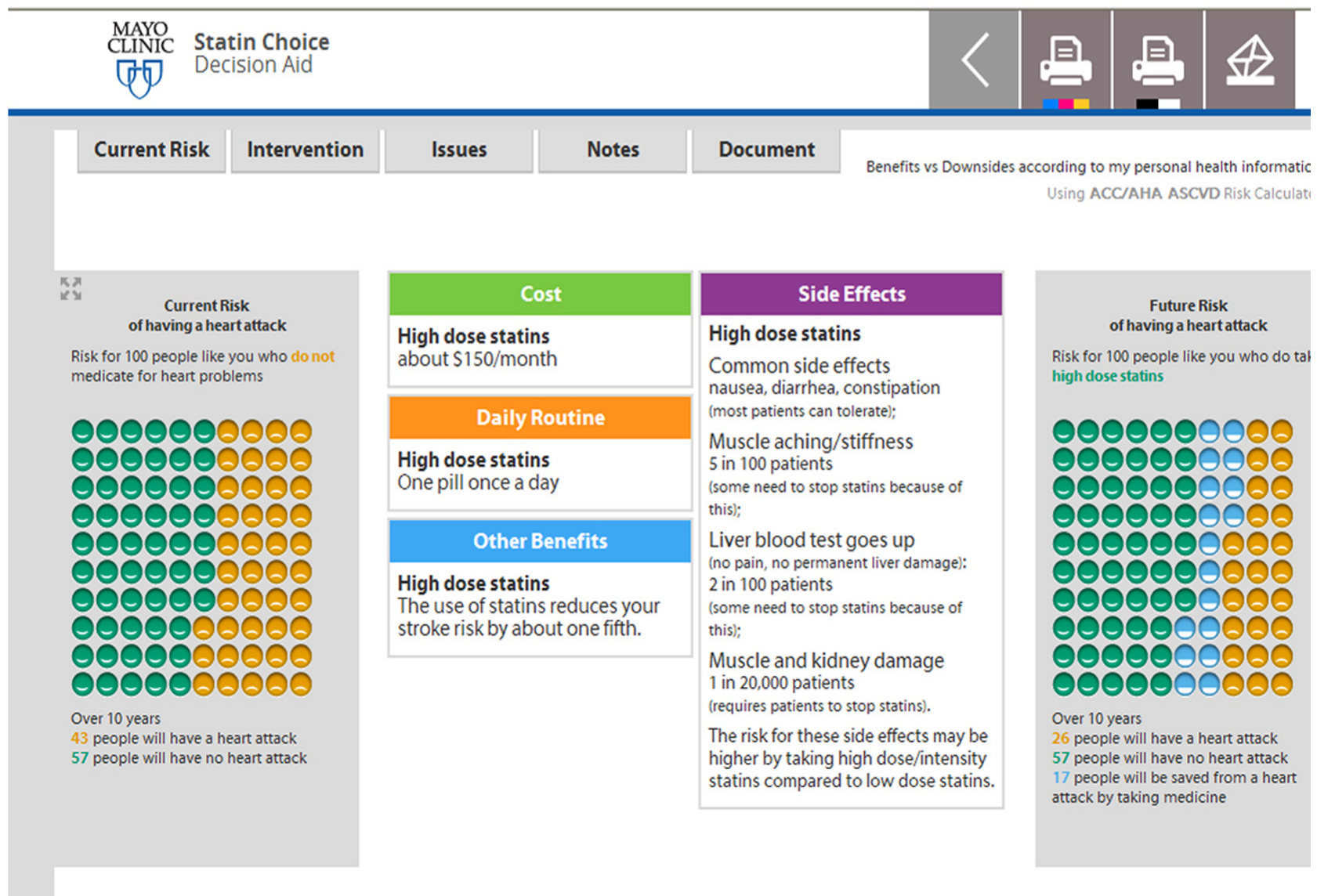

Figure 2 Decision aid of Statin Choice (left: paper cards; right: online decision aid)

Note: Used with permission of Mayo Foundation for Medical Education and Research. All Rights reserved. ${ }^{24}$ 
Training included a Chinese language video demonstration of how the tool should be used in practice. It also emphasized the role of decision aids as guides for conversation rather than a script to be recited. We encouraged clinicians to exercise their own judgment in determining how and when to use the decision aid during a visit. However, all patients enrolled in this study were exposed to decision aid (DA). A study team member remained available for further, one-on-one demonstrations as needed.

\section{Encounter intervention}

The intervention consisted of the use of Chinese and English language versions of the Statin Choice decision aid by patients and clinicians during the clinical encounter. All clinicians used the decision aid during the SDM process.

The Chinese version of the DA was paper based, and there were three versions: average risk (used for patients with a 10 -year cardiovascular risk $<15 \%$ ), elevated risk (for patients with estimated risk between $15 \%$ and $30 \%$ ), or high risk (for patients with estimated risk $>30 \%$ ). These cutoffs were arbitrary and consistent with the use of the paper-based Statin Choice, tool in the US trials. ${ }^{6,7}$ Using the web-based English version of the tool (http://statindecisionaid.mayoclinic.org/), clinicians calculated the individualized 10-year cardiovascular risk for a patient and then selected the most appropriate one for their patients from the three Chinese language versions. Both versions were used throughout the encounter as necessary. Both versions present the absolute risk reduction in cardiovascular events with statins, using numbers, phrases, and an icon array representing " 100 people like you over the next 10 years". ${ }^{9}$ The DA also presented expected inconveniences and potential side effects.

During the conduct of the study, it became obvious that some patients had limited health literacy and had trouble in understanding the tool. Therefore, part way through the study, we decided to carry out group patient education once a week to introduce general knowledge about coronary artery disease (such as what is coronary artery disease, what are the major adverse events of them, why patients with coronary artery disease must use statin, etc).

\section{Evaluation}

\section{SDM outcomes}

All the clinical encounters were video recorded. The patients' demographic and clinical characteristics were collected. The clinician's demographic characteristics were also recorded.

A team of three researchers viewed and scored all the encounter recordings using the OPTION scale ${ }^{10,11}$ and a

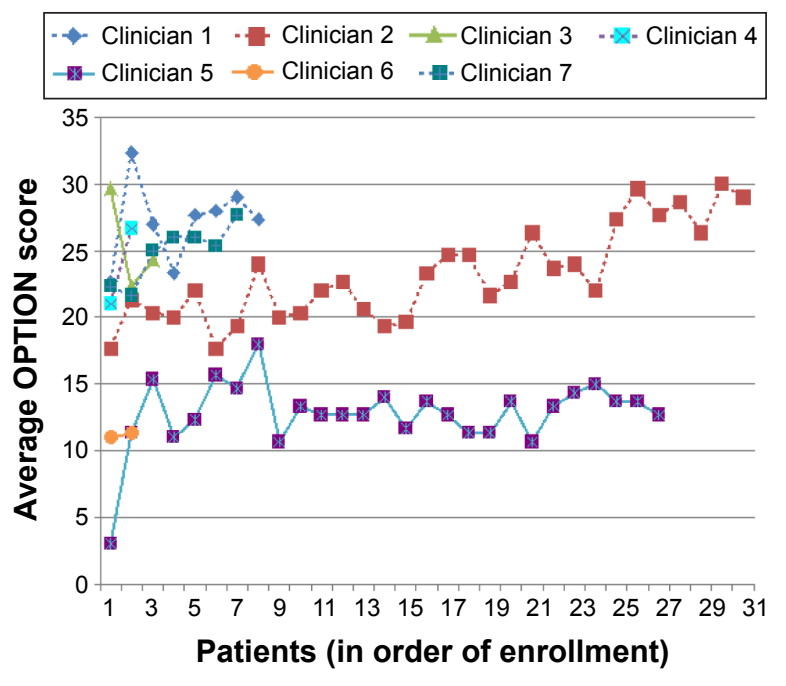

Figure 3 The continuous average OPTION scores of the clinicians by time.

Fidelity scale ${ }^{12}$ (Tables S1 and S2, Figure S1). They were all cardiologists with $>10$ years of clinical experience. The OPTION scale is a 12 -item 5 -point scale (from 0 [behavior not observed] to 4 [high standard]), awarded based on an observed clinician's effort to engage patients in decision making according to a scoring manual. ${ }^{10,11}$ The raw total score ranges from 0 ( 0 on all items) to 48 ( 4 on all items). Scores are rescaled into a $0-100$ range. The Fidelity scale, developed from previous trials of the Statin Choice decision aid, ${ }^{12}$ is a 10 -item checklist noting whether a behavior important in the intended use of the tools is present (score of 1) or absent (score of 0 ) for a range of $0-10$ points per encounter. Before scoring all videos, researchers received training in the use of both scales. After initial training, the three researchers scored three sample videos independently and in triplicate. Disagreements were resolved by consensus, followed by six videos reviewed separately and another consensus process occurred. During the scoring process, the researchers recorded the total time spent on SDM and used the OPTION scale ${ }^{10,11}$ (Figure S1) to assess the SDM process and the Fidelity scale ${ }^{12}$ to assess the use of the Statin Choice decision aid as intended (Figure 3).

\section{Adherence and clinical outcomes}

We used pharmacy records for the 12-month period post enrollment to estimate adherence to medications added or changed during the index encounter. Patients who chose not to start a statin at the index encounter were not included in this portion of the analysis. This estimate of statin adherence was calculated using the percentage of days covered (PDC) of 365 days after the clinical encounter with their clinician, which was defined as the number of days a patient had statin. We also calculated the proportion of patients who were 
adherent (defined as PDC covered $\geq 80 \%$ of days) to that study drug throughout the follow-up period. All side effects to statin therapy were recorded. The safety was determined by the prevalence of major adverse cardiac events (MACE), including cardiac death, myocardial infarction, unstable angina, heart failure, and coronary revascularization within 12 months of the primary visit.

\section{Statistical analysis}

Values for continuous variables that did not approximate a normal distribution are presented as median (range), unless otherwise noted. To examine inter-rater reliability and intra-rater reliability between raters, we used percentage agreement, Cohen's weighted $\kappa,{ }^{13}$ and intraclass correlations (ICCs). Statistical analyses were performed using SPSS software (Version 17.0; SPSS Inc., Chicago, IL, USA).

\section{Results}

Seven clinicians participated in this study (Table 1), of whom two (one in each hospital) contributed a large share of the encounters. The average total time of the encounters was 15 minutes (range, 5-38 minutes), of which 12 were spent on SDM (range, 3-13 minutes).

We enrolled 86 patients with stable angina in this study, of whom six refused to be videotaped (Table 1). Of these patients, 56 patients were males. Participants were at high cardiovascular risk; most were retired and living in urban areas, and had health insurance. Approximately $43 \%$ of patients had at least a high school level of education. Although the number of clinicians was small, we did not find that the variability in behavior and uptake of SDM among them was attributable to sex, clinical experience, or patients with different levels of education.

Video review had adequate reproducibility. Reviewers were consistent in rating each item of the fidelity checklist (ICC, 0.61 ; 95\% CI, 0.47-0.73) and in rating each encounter using the checklist (ICC, 0.92; 95\% CI, 0.88-0.94; Tables S1 and S2, Figure S1). Reviewers were also consistent in rating each item of the OPTION score (ICC, 0.94; 95\% CI, $0.92-0.96$ ) and in rating each encounter using the OPTION

Table I Participants' characteristics

\begin{tabular}{|c|c|c|c|c|c|c|c|c|}
\hline \multirow[t]{2}{*}{ Characteristics } & \multicolumn{4}{|l|}{ Hospital A } & \multicolumn{3}{|l|}{ Hospital B } & \multirow{2}{*}{$\frac{\text { Total }}{\text { All }}$} \\
\hline & Clinician I & Clinician 2 & Clinician 3 & Clinician 4 & Clinician 5 & Clinician 6 & Clinician 7 & \\
\hline \multicolumn{9}{|l|}{ Patients' characteristics } \\
\hline Number of encounters & 8 & 31 & 2 & 7 & 27 & 3 & 2 & 80 \\
\hline Sex, male, n (\%) & $7(88)$ & $17(55)$ & $2(100)$ & $6(86)$ & $23(85)$ & I (33) & $0(0)$ & $56(70)$ \\
\hline Age (years), median (range) & $63(44,76)$ & $66(44,78)$ & $76(72,79)$ & $55(45,71)$ & $6 I(4 I, 77)$ & $57(44,59)$ & $55(54,56)$ & $62(41,79)$ \\
\hline Current smoker, n (\%) & $7(88)$ & II (36) & $0(0)$ & $2(29)$ & $10(37)$ & I (33) & I (50) & $32(40)$ \\
\hline Atrial fibrillation, n (\%) & I (I3) & I (3) & $0(0)$ & $0(0)$ & $2(7)$ & I (33) & $0(0)$ & $5(6)$ \\
\hline Coronary heart diseases, n (\%) & $5(63)$ & $26(84)$ & $2(100)$ & $4(57)$ & $25(93)$ & $3(100)$ & I (50) & $66(83)$ \\
\hline Previous myocardial infarction, n (\%) & I (I3) & $3(10)$ & $0(0)$ & I (I4) & I (4) & $0(0)$ & $0(0)$ & $6(8)$ \\
\hline Hypertension, n (\%) & $7(88)$ & $27(87)$ & I (50) & $5(7 I)$ & $15(56)$ & $2(67)$ & $0(0)$ & $57(7 \mathrm{I})$ \\
\hline Diabetes, n (\%) & $3(38)$ & $12(39)$ & I (50) & $4(57)$ & $10(37)$ & $2(67)$ & $0(0)$ & $32(40)$ \\
\hline Taking aspirin before enrollment, n (\%) & $2(25)$ & $15(48)^{a}$ & I (50) & I (I4) & $27(100)$ & $0(0)$ & I $(50)^{b}$ & $47(59)^{c}$ \\
\hline Taking statin before enrollment, n (\%) & I (I3) & $6(19)$ & $0(0)$ & I (I4) & $26(96)$ & $0(0)$ & $(50)^{b}$ & $35(44)^{d}$ \\
\hline Education $\geq$ high school, n (\%) & $4(50)$ & $10(32)$ & $0(0)$ & $4(57)$ & I5 $(56)^{\mathrm{e}}$ & I (33) & $0(0)$ & $34(43)^{c}$ \\
\hline Self-reported illiterate, n (\%) & $0(0)$ & $2(7)$ & $0(0)$ & I (I4) & $0(0)$ & I (33) & $0(0)$ & $4(5)^{d}$ \\
\hline Employed, n (\%) & $0(0)$ & $6(19)$ & $0(0)$ & $4(57)$ & $6(22)$ & I (33) & $2(100)$ & $19(24)$ \\
\hline Retired, n (\%) & $5(63)$ & $15(48)$ & I (50) & $3(43)$ & $15(56)^{f}$ & $2(67)$ & $0(0)$ & $4 I(5 I)^{g}$ \\
\hline With health insurance, n (\%) & $8(100)$ & $31(100)$ & $2(100)$ & $7(100)$ & $26(96)$ & $3(100)$ & I (50) & $78(98)$ \\
\hline Living in rural area, n (\%) & $4(50)$ & $9(29)$ & $0(0)$ & I (14) & $3(11)$ & I (33) & $0(0)$ & $18(23)$ \\
\hline $\begin{array}{l}\text { Received patient education before } \\
\text { enrollment, } \mathrm{n}(\%)\end{array}$ & I (I3) & II (36) & I (50) & I (I4) & $0(0)$ & $0(0)$ & $0(0)$ & $14(18)$ \\
\hline SDM time (minutes), median (range) & $14(12,31)$ & $13(8,30)$ & $13(9,19)$ & $20(10,22)$ & $6(3,11)$ & $14(12,15)$ & $10(6,14)$ & $12(3,31)$ \\
\hline Total time (minutes), median (range) & $18(15,38)$ & $18(9,39)$ & $20(13,28)$ & $21(15,24)$ & $9(5,19)$ & $17(13,18)$ & $13(6,20)$ & $15(5,38)$ \\
\hline \multicolumn{9}{|l|}{ Clinicians' characteristics } \\
\hline Sex & Female & Male & Female & Male & Female & Male & Female & - \\
\hline Age (years) & 41 & 28 & 27 & 35 & 30 & 41 & 27 & - \\
\hline Medical education & MD & MS & MS & MD & MS & MD & MD & - \\
\hline Years as a cardiologist & 18 & 2 & 2 & 9 & 5 & 18 & 4 & - \\
\hline
\end{tabular}

Notes: a Data on 30 of 31 (97\%). ${ }^{b}$ Data on I of 2 (50\%). ' ${ }^{\mathrm{C}}$ ata on 78 of 80 (98\%). ${ }^{\mathrm{d} D a t a}$ on 79 of 80 (99\%). ${ }^{\mathrm{e} D a t a}$ on 25 of 27 (93\%). ${ }^{\mathrm{f} D a t a}$ on 23 of 27 (85\%). ${ }^{8}$ Data on 76 of 80 (95\%).

Abbreviations: SDM, shared decision making; MD, Doctor of Medicine; MS, Master of Medicine. 
Table 2 Average Fidelity score (percentage of yes responses)

\begin{tabular}{|c|c|c|c|c|c|c|c|c|}
\hline \multirow[t]{2}{*}{ Items } & \multicolumn{4}{|l|}{ Hospital A } & \multicolumn{3}{|l|}{ Hospital B } & \multirow[t]{2}{*}{ Overall } \\
\hline & $\begin{array}{l}\text { Clinician I } \\
(\mathrm{n}=8)\end{array}$ & $\begin{array}{l}\text { Clinician } 2 \\
(n=31)\end{array}$ & $\begin{array}{l}\text { Clinician } 3 \\
(\mathrm{n}=2)\end{array}$ & $\begin{array}{l}\text { Clinician } 4 \\
(n=7)\end{array}$ & $\begin{array}{l}\text { Clinician } 5 \\
(n=27)\end{array}$ & $\begin{array}{l}\text { Clinician } 6 \\
(n=3)\end{array}$ & $\begin{array}{l}\text { Clinician } 7 \\
(n=2)\end{array}$ & \\
\hline $\begin{array}{l}\text { Describe the risk as } \\
\text { a natural frequency }\end{array}$ & 100 & 100 & 100 & 100 & 100 & 100 & 100 & 100 \\
\hline $\begin{array}{l}2 \text { Describe the time horizon for } \\
\text { the risk of having a heart attack }\end{array}$ & 100 & 100 & 83 & 81 & 28 & 100 & 83 & 82 \\
\hline 3 Describe the risk graphically & 100 & 100 & 100 & 100 & 100 & 100 & 100 & 100 \\
\hline $\begin{array}{l}4 \text { Describe the risk reduction } \\
\text { as a natural frequency }\end{array}$ & 100 & 100 & 100 & 100 & 96 & 100 & 100 & 99 \\
\hline $\begin{array}{l}5 \text { Describe the time horizon } \\
\text { for the risk reduction }\end{array}$ & 100 & 99 & 100 & 86 & 30 & 100 & 67 & 83 \\
\hline $\begin{array}{l}6 \text { Describe the risk reduction } \\
\text { graphically }\end{array}$ & 100 & 100 & 100 & 100 & 100 & 100 & 100 & 100 \\
\hline $\begin{array}{l}7 \text { Describe the duration of taking } \\
\text { the statin }\end{array}$ & 100 & 96 & 100 & 96 & 33 & 100 & 50 & 82 \\
\hline $\begin{array}{l}8 \text { Describe at least one of the } \\
\text { common side effects }\end{array}$ & 95.8 & 94 & 100 & 100 & 99 & 100 & 100 & 98 \\
\hline $\begin{array}{l}9 \text { Describe the frequency of at } \\
\text { least one of the side effects }\end{array}$ & 95.8 & 92 & 100 & 100 & 96 & 100 & 83 & 95 \\
\hline $\begin{array}{l}10 \text { Describe the cost of the } \\
\text { medication }\end{array}$ & 100 & 98 & 100 & 100 & 98 & 78 & 100 & 96 \\
\hline Overall Fidelity score & 99 & 98 & 98 & 96 & 78 & 98 & 90 & 94 \\
\hline
\end{tabular}

Notes: Average Fidelity scale is 10 (range, 6-10; out of possible, 10). All videos were scored independently and in triplicate.

scale (ICC, 0.93; 95\% CI, 0.90-0.95; Tables S1 and S2, Figure S1). The fidelity to the use of the decision aid (Table 2) was optimal except for two clinicians, who also exhibited fewer behaviors consistent with engaging patients in SDM, as judged by their OPTION scores (Table 3). The average scores on the OPTION normalized score and Fidelity scales were 44 (range, 6-67) and 10 (range, 6-10; out of a possible 10), respectively. The most common item

Table 3 Average OPTION score, median (range)

\begin{tabular}{|c|c|c|c|c|c|c|c|c|}
\hline Items & \multicolumn{4}{|l|}{ Hospital A } & \multicolumn{3}{|l|}{ Hospital B } & \multirow[t]{2}{*}{ Overall } \\
\hline & $\begin{array}{l}\text { Clinician I } \\
(n=8)\end{array}$ & $\begin{array}{l}\text { Clinician } 2 \\
(n=31)\end{array}$ & $\begin{array}{l}\text { Clinician } 3 \\
(\mathrm{n}=2)\end{array}$ & $\begin{array}{l}\text { Clinician } 4 \\
(n=7)\end{array}$ & $\begin{array}{l}\text { Clinician } 5 \\
(n=27)\end{array}$ & $\begin{array}{l}\text { Clinician } 6 \\
(n=3)\end{array}$ & $\begin{array}{l}\text { Clinician } 7 \\
(n=2)\end{array}$ & \\
\hline $\begin{array}{l}\text { I Draw attention to a problem that } \\
\text { requires a decision-making process }\end{array}$ & $2.0(1.7-2.3)$ & $1.7(0.7-2.3)$ & $1.5(1.3-1.7)$ & $2.0(1.3-2.0)$ & $0.7(0.3-1.3)$ & $1.7(1.3-2.0)$ & $0.8(0.7-1.0)$ & $1.3(0.3-2.3)$ \\
\hline 2 State more than one option & $1.5(0.7-1.7)$ & $0.7(0.7-2.0)$ & $1.0(0.7-1.3)$ & $1.0(1.0-1.7)$ & $0.7(0-1.0)$ & $1.3(1.0-1.7)$ & $0.7(0.3-1.0)$ & $0.7(0-2.0)$ \\
\hline $\begin{array}{l}3 \text { Assess patient's preferred } \\
\text { approach to receiving information }\end{array}$ & $2.0(1.3-2.7)$ & $1.7(1.0-2.3)$ & $1.7(1.3-2.0)$ & $1.7(1.3-2.3)$ & $1.7(0.7-1.7)$ & $2.0(1.7-2.3)$ & $0.8(0.3-1.3)$ & $1.7(0.3-2.7)$ \\
\hline 4 List options & $1.7(1.0-2.3)$ & $1.3(0.7-2.3)$ & $1.5(1.3-1.7)$ & $1.3(1.0-1.7)$ & $0.7(0.3-1.7)$ & $1.3(1.3-2.3)$ & $0.8(0.3-1.3)$ & $1.2(0.3-2.3)$ \\
\hline $\begin{array}{l}5 \text { Explain the pros and cons of } \\
\text { options }\end{array}$ & $2.3(1.7-2.7)$ & $2.0(1.3-2.7)$ & $2.0(1.7-2.3)$ & $2.3(1.7-2.7)$ & $1.3(1.0-2.0)$ & $2.0(2.0-2.3)$ & $1.3(1.0-1.7)$ & $1.7(1.0-2.7)$ \\
\hline 6 Explore the patient's expectations & $2.2(1.7-2.3)$ & $2.0(1.0-2.3)$ & $1.8(1.7-2.0)$ & $2.0(1.7-2.3)$ & $1.0(0.7-1.7)$ & $2.0(1.7-2.0)$ & $1.2(1.0-1.3)$ & $1.7(0.7-2.3)$ \\
\hline 7 Explore the patient's concerns & $2.0(1.7-2.3)$ & $1.7(1.3-2.7)$ & $1.8(1.7-2.0)$ & $2.0(2.0-2.7)$ & $0.7(0-1.3)$ & $1.7(1.3-2.3)$ & $0.5(0.3-0.7)$ & $1.7(0-2.7)$ \\
\hline $\begin{array}{l}8 \text { Check the patient has understood } \\
\text { the information }\end{array}$ & $2.0(0.7-2.7)$ & $1.7(1.0-2.3)$ & $1.8(1.3-2.3)$ & $2.3(2.0-2.7)$ & $1.7(0.5-2.0)$ & $2.0(2.0-2.3)$ & $1.2(1.0-1.3)$ & $1.7(0.5-2.7)$ \\
\hline $\begin{array}{l}9 \text { Offer the patient explicit } \\
\text { opportunities to ask questions }\end{array}$ & $2.0(1.3-2.7)$ & $1.7(1.0-2.7)$ & $1.8(1.7-2.0)$ & $2.0(1.7-2.3)$ & $1.0(0-1.7)$ & $2.0(1.7-2.7)$ & $0.8(0.7-1.0)$ & $1.7(0-2.7)$ \\
\hline $\begin{array}{l}\text { I0 Elicit the patient's preferred level } \\
\text { of involvement }\end{array}$ & $2.0(1.3-2.3)$ & $2.0(1.3-2.7)$ & $1.8(1.7-2.0)$ & $2.0(1.7-2.3)$ & $1.0(0-1.3)$ & $2.0(1.3-2.3)$ & $1.3(1.3-1.3)$ & $1.7(0-2.7)$ \\
\hline $\begin{array}{l}\text { II Indicate the need for a } \\
\text { decision-making stage }\end{array}$ & $1.8(1.3-2.3)$ & $1.7(1.0-2.0)$ & $1.5(1.3-1.7)$ & $1.7(1.7-2.0)$ & $0.7(0-1.0)$ & $1.3(1.3-1.7)$ & $0.8(0.7-1.0)$ & $1.3(0-2.3)$ \\
\hline $\begin{array}{l}12 \text { Indicate the need to review } \\
\text { the decision }\end{array}$ & $0.8(0-2.0)$ & $0.3(0-1.7)$ & $0.3(0-0.7)$ & $0.3(0-0.7)$ & $0.3(1-1.0)$ & $0.3(0-0.3)$ & $0.7(0-1.3)$ & $0.3(0-2.0)$ \\
\hline Overall score & $28(23-32)$ & $23(18-30)$ & $24(2 \mid-27)$ & $25(22-28)$ & $13(3-18)$ & $24(22-30)$ & $I I(I I-I I)$ & $21(3-32)$ \\
\hline Overall normalized score ${ }^{a}$ & $57(47-67)$ & $47(37-62)$ & $50(44-56)$ & $53(45-58)$ & $26(6-37)$ & $5 \mathrm{I}(47-62)$ & $23(23-24)$ & $44(6-67)$ \\
\hline
\end{tabular}


of the decision aid that was not implemented properly was the description of the time horizons for risk and risk reduction, ie, they would not use a sentence such as "in the next 10 years" or "within the next 10 years" (item 2 and item 5 in the Fidelity scale). If the clinicians did not emphasize the time horizons for risk and risk reduction with such sentence, the reviewer scored it as " 0 " of item 2 or item 5 according to the Fidelity scale list. If the patient misunderstood the extent of risk, they might make a different medical decision than if they had understood the risk. OPTION scores indicated that most clinicians did not explicitly indicate that 1) both taking and not taking statins were reasonable options (recall that most patients were at high risk, and for some clinicians the rate of statin use at baseline was 50\%-96\%) and 2) the decision made could be reviewed and revised in the future. The clinicians with the lowest scores presented information but offered minimal opportunities for patients to ask questions, express their own thoughts, or participate more fully in deliberation. There was a trend toward better OPTION scores with more experience using the decision aid (Figure 3).

After 12 months (Table 4), seven patients refused to provide their pharmacy records; of the other 73 patients, 69 had a PDC $\geq 80 \%$. The rate of statin adherence in patients with coronary artery diseases in usual care has been reported to be $60 \% .{ }^{14,15}$ Lower rates of adherence may be related to increased rates of MACEs. ${ }^{15,16}$ In this study, among all patients who were adherent to statin therapy, one died of intestinal obstruction. Two patients underwent percutaneous coronary intervention because of recurrent angina. Out of the four patients who stopped taking statin, one stopped due to muscle aches and the other three to avoid out-of-pocket costs. One patient had recurrent angina and another had an acute myocardial infarction and had stents implanted.

Table 4 Clinical outcomes at I 2-month follow-up $(n=73)$

\begin{tabular}{|c|c|c|}
\hline Clinical outcomes & $\begin{array}{l}\text { Statin PDC } \\
<80 \%(n=4)\end{array}$ & $\begin{array}{l}\text { Statin PDC } \\
\geq 80 \%(n=69)\end{array}$ \\
\hline \multicolumn{3}{|l|}{ Side effects of statin } \\
\hline Muscle aches or myalgia (n, \%) & I, 25 & 0 \\
\hline Elevated levels of CPK $(n, \%)$ & I, 25 & $2,2.9$ \\
\hline \multicolumn{3}{|l|}{ MACEs } \\
\hline All-cause mortality (n, \%) & 0 & I, I.4 \\
\hline Cardiac death $(n, \%)$ & 0 & 0 \\
\hline Acute myocardial infarction ( $\mathrm{n}, \%)$ & $\mathrm{I}, 25$ & 0 \\
\hline Angina $(\mathrm{n}, \%)$ & I, 25 & $2,2.9$ \\
\hline Coronary revascularization (n, \%) & I, 25 & $2,2.9$ \\
\hline Heart failure (n, \%) & 0 & 0 \\
\hline
\end{tabular}

Abbreviations: CPK, creatine phosphokinase; MACEs, major adverse cardiac events; PDC, percentage of days covered.

\section{Discussion Our findings}

In this study of the first experience of SDM in Mainland China, although a few clinicians did not perform SDM like others, we found that most Chinese clinicians using a decision aid in patients with stable angina were able to exhibit behaviors consistent with SDM at a level that is similar to that reported in Western countries. ${ }^{17}$ We found that in our population when patients engaged in SDM and chose to take a statin, adherence was high, which hopefully over time will result in fewer MACEs. ${ }^{15,16,18}$ Although the sample of clinicians was small, we were able to observe some variability in behavior and uptake of SDM that was not easily attributable to sex, clinical experience, or length of the patient-clinician relationship. We also did not identify marked differences in SDM across encounters with patients with different levels of education.

\section{Limitations of these observations}

Our study has some key limitations. The patients in these encounters were not representative of the average Chinese patient due to economic and regional differences, ${ }^{19,20}$ which may limit the applicability. The hospitals mentioned in this study are both teaching hospitals and located in large Northern cities. Only $23 \%$ of patients came from rural areas and $98 \%$ of patients were covered by health insurance. In the general population, half of all Chinese patients live in rural areas with low levels of education. ${ }^{20}$ However, similar to our sample, $95 \%$ of the total Chinese population is covered by health insurance. ${ }^{20}$ In addition, in the practices where the study was conducted, clinicians are usually able to spend more time with patients with limited literacy to explain basic medical knowledge. In support of this observation, we found that after we implemented patient education prior to the SDM encounter, the time spent in performing SDM decreased from 12 minutes to an average of 7 minutes. Among patients who received the group education, the OPTION scores were higher, but this could also reflect clinicians becoming more comfortable with the tool and SDM as the study progressed. Further studies should be performed to elucidate the effect of both pre-encounter education and learning curves on SDM. Any improvements would be valuable not only from an SDM perspective but also because of the reduction in encounter duration, and these improvements may make implementing SDM more feasible.

The physical environment in which we tested SDM also introduces some limitations. We noted that in some cases the extent to which clinicians involved patients in decision making was influenced by other factors, including 
interruptions, noise, and distractions created by phone calls or by clinicians or patients' relatives, other patients, or other people waiting or having conversations in the same room, especially in the cases of clinicians 5 and 7. For example, in one case, there was another clinician discussing an angiogram with his patient in the same room. The patient in our study obviously shifted attention away and even turned his head to the other clinician. Eventually, he left the SDM conversation and instead engaged with the other clinician and patient in the angiogram discussion. This has been observed in another health system in South America. ${ }^{21}$ The requirements for uninterrupted discussion and privacy need to be explored further to determine their impact on the feasibility of SDM in China, as one-on-one encounters with no one else present are not the norm in China.

The role of others was also apparent in this study and, in some cases, in a dominant way. In one case, at the outset of the conversation, an elderly woman sat next to the clinician. Her two daughters stood behind their mother. The patient tried her best to participate, but very soon her daughters took over the conversation. One of them displaced her mother and sat next to the clinician, asked many questions, and made a decision for her mother who stood silent and further away. Cultural expectations about the role of family members will also need to be carefully taken into account when implementing SDM in China.

The intervention itself introduced some limitations. Beyond language (the electronic tool is now available in Chinese), the tool's content was a subject of concern. Beyond the language translation of the tool, no further modifications were made. Therefore, the cost, issues, side effects, and effectiveness data are derived from Western populations and may not be applicable in the Chinese context; further modification may be needed prior to a large-scale study or implementation efforts. In addition, more robust mixed-method studies should be performed to further explore the feasibility, acceptability, and effectiveness of SDM interventions in China.

\section{Implications for research}

This feasibility study showed that introducing SDM into practice is feasible in a highly selected setting. Understanding the professional and patient drivers for SDM could also be fruitful. For example, specific and teachable physician-patient communication behaviors, including SDM, are associated with fewer malpractice claims for physicians. $^{22}$ Thus, Chinese physicians concerned about the impact of malpractice risk could be motivated to improve their communication skills, in turn promoting the adoption of curricula in SDM and patient-centered communication in medical schools and postgraduate training programs. ${ }^{4}$ Medical sociology studies focused on the work of sharing decision making may also uncover the roles that patients and clinicians could play. ${ }^{23}$ Design researchers could work together with Chinese patients and clinicians to devise culturally and context-sensitive tools, training, and services that might facilitate SDM, and subject these to empirical testing. Further testing of SDM tools developed elsewhere in usual Chinese practice may provide further insight into the unique nature of the Chinese setting: how practices deal with the demands for decision-making time, how patients respond to the invitation to participate in choice, and how clinicians and patients handle situations in which they disagree.

Finally, the successful implementation of SDM will need support from policy makers, particularly the Chinese government. ${ }^{4}$ This support may include investments to allow for longer appointments (eg, by improving access and quality of care in the community and thus reducing the demand for specialized care in urban hospitals) and better access to and affordability of important evidence-based treatment options, especially in rural areas.

\section{Conclusion}

SDM through the implementation of encounter decision aids appears feasible in Mainland China. The extent, scope, and effectiveness of SDM need to be explored further. This exploration should bear in mind the characteristics of health care, patients, clinicians, and evidence pertinent to the Chinese context to design SDM interventions for that particular context. When successful, SDM will contribute to evidence-based patient-centered care for Chinese patients.

\section{Acknowledgments}

The authors thank Doctor Shuting Li, Doctor Yafei Lu, and other nursing staff of Cardiology Department of the First Affiliated Hospital of Dalian Medical University and Doctor Dongfeng Zhang from Beijing An Zhen Hospital, Capital Medical University for data collection and patient communication; Doctor Baolin $\mathrm{Wu}$ and $\mathrm{Ms} \mathrm{Na} \mathrm{Xu}$ for the follow-up of patients; and Ms Qi Li and Doctor Huaiyu Ding for reviewing and scoring all the videos. MRG was supported by CTSA Grant Number TL1 TR000137 from the National Center for Advancing Translational Science. The contents of this manuscript are solely the responsibility of the authors and do not necessarily represent the official views of the National Institutes of Health. 


\section{Disclosure}

The authors report no conflicts of interest in this work.

\section{References}

1. Hoffman TC, Montori VM, Mar CD. The connection between evidencebased medicine and shared decision making. JAMA. 2014;312(13): 1295-1296.

2. Barry MJ, Edgman-Levitan S. Shared decision making - pinnacle of patient-centered care. N Engl J Med. 2012;366(9):780-781.

3. Elwyn G, Lloyd A, May C, et al. Collaborative deliberation: a model for patient care. Patient Educ Couns. 2014;97(2):158-164.

4. Huang R, Gionfriddo MR, Zhang L, et al. Shared decision making in China: current status and future directions. Patient Prefer Adherence. 2015;9:1129-1141.

5. Nannenga MR, Montori VM, Weymiller AJ, et al. A treatment decision aid may increase patient trust in the diabetes specialist. The statin choice randomized trial. Health Expect. 2009;12(1):38-44.

6. Weymiller AJ, Montori VM, Jones LA, et al. Helping patients with type 2 diabetes mellitus make treatment decisions: statin choice randomized trial. Arch Intern Med. 2007;167:1076-1082.

7. Mann DM, Ponieman D, Montori VM, Arciniega J, McGinn T. The statin choice decision aid in primary care: a randomized trial. Patient Educ Couns. 2010;80(1):138-140.

8. Fihn SD, Blankenship JC, Alexander KP, et al. 2014 ACC/AHA/AATS/ PCNA/SCAI/STS focused update of the guideline for the diagnosis and management of patients with stable ischemic heart disease: a report of the American College of Cardiology/American Heart Association Task Force on Practice Guidelines, and the American Association for Thoracic Surgery, Preventive Cardiovascular Nurses Association, Society for Cardiovascular Angiography and Interventions, and Society of Thoracic Surgeons. Circulation. 2014;130(19):1749-1767.

9. Montori VM, Breslin M, Maleska M, Weymiller A. Creating a conversation: insights from the development of a decision aid. PLoS Med. 2007;4(8):e233.

10. Elwyn G, Hutchings H, Edwards A, et al. The OPTION scale: measuring the extent that clinicians involve patients in decision-making tasks. Health Expect. 2005;8(1):34-42.

11. Elwyn G, Edwards A, Wensing M, Hood K, Atwell C, Grol R. Shared decision making: developing the OPTION scale for measuring patient involvement. Qual Saf Health Care. 2003;12(2):93-99.
12. Branda ME, LeBlanc A, Shah ND, et al. Shared decision making for patients with type 2 diabetes: a randomized trial in primary care. $B M C$ Health Serv Res. 2013;13:301.

13. Warrens M. Cohen's linearly weighted kappa is a weighted average. Adv Data Anal Classif. 2012;6:67-79.

14. Gamboa CM, Safford MM, Levitan EB, et al. Statin underuse and low prevalence of LDL-C control among U.S. adults at high risk of coronary heart disease. Am J Med Sci. 2014;348(2):108-114.

15. Chowdhury R, Khan H, Heydon E, et al. Adherence to cardiovascular therapy: a meta-analysis of prevalence and clinical consequences. Eur Heart J. 2013;34(38):2940-2948.

16. Ho P, Magid D, Masoudi F, McClure D, Rumsfeld J. Adherence to cardioprotective medications and mortality among patients with diabetes and ischemic heart disease. BMC Cardiovasc Disord. 2006;6:48.

17. Couët N, Desroches S, Robitaille H, et al. Assessments of the extent to which health-care providers involve patients in decision making: a systematic review of studies using the OPTION instrument. Health Expect. 2015;18(4):542-561.

18. De Vera MA, Bhole V, Burns LC, Lacaille D. Impact of statin adherence on cardiovascular disease and mortality outcomes: a systematic review. Br J Clin Pharmacol. 2014;78(4):684-698.

19. The Report on the National Survey of Aging Population Distribution in the Urban and Rural Area of China (Complete Version). Beijing: China NBoSo; 2010. Chinese.

20. Statistical Communique of the People's Republic of China on the 2012 National Economic and Social Development. Beijing: China NBoSo; 2013. Chinese.

21. Gravel K, Légaré F, Graham ID. Barriers and facilitators to implementing shared decision-making in clinical practice: a systematic review of health professionals' perceptions. Implement Sci. 2006;1:16.

22. Durand MA, Moulton B, Cockle E, Mann M, Elwyn G. Can shared decision-making reduce medical malpractice litigation? A systematic review. BMC Health Serv Res. 2015;15:167.

23. Tiedje K, Shippee N, Johnson A, et al. 'They leave at least believing they had a part in the discussion': understanding decision aid use and patient-clinician decision-making through qualitative research. Patient Educ Couns. 2013;93(1):86-94.

24. Statin Choice Decision Aid [homepage on the Internet]. Mayo Clinic. Available from: http://statindecisionaid.mayoclinic.org. Accessed October 18, 2016. 


\section{Supplementary materials}

Table SI OPTION scale, median (range)

\begin{tabular}{|c|c|c|c|c|c|c|c|}
\hline \multirow[t]{2}{*}{ Reviewers } & \multicolumn{4}{|l|}{ Hospital A } & \multicolumn{3}{|l|}{ Hospital B } \\
\hline & Clinician I & Clinician 2 & Clinician 3 & $\overline{\text { Clinician } 4}$ & Clinician 5 & Clinician 6 & Clinician 7 \\
\hline I & $30(24-35)$ & $25(17-35)$ & $25(2 \mid-29)$ & $29(22-34)$ & $14(6-20)$ & $26(26-33)$ & $10(9-11)$ \\
\hline 2 & $28(19-35)$ & $22(14-30)$ & $24(22-25)$ & $25(24-31)$ & $9(3-18)$ & $21(20-33)$ & $16(15-16)$ \\
\hline 3 & $25(19-28)$ & $20(17-30)$ & $23(20-26)$ & $20(19-21)$ & $14(4-19)$ & $23(20-27)$ & $8(8-8)$ \\
\hline Overall & $28(23-32)$ & $23(18-30)$ & $24(2 \mid-27)$ & $25(22-28)$ & $13(3-18)$ & $24(22-30)$ & $I I(I I-I I)$ \\
\hline Overall normalized score & $57(47-67)$ & $47(37-62)$ & $50(44-56)$ & $53(45-58)$ & $26(6-37)$ & $51(47-62)$ & $23(23-24)$ \\
\hline
\end{tabular}

Note: All videos were scored independently and in triplicate.

Table S2 Fidelity scale, median (range)

\begin{tabular}{|c|c|c|c|c|c|c|c|}
\hline \multirow[t]{2}{*}{ Reviewers } & \multicolumn{4}{|l|}{ Hospital A } & \multicolumn{3}{|l|}{ Hospital B } \\
\hline & Clinician I & Clinician 2 & Clinician 3 & Clinician 4 & Clinician 5 & Clinician 6 & Clinician 7 \\
\hline I & $10(10-10)$ & $10(8-10)$ & $10(10-10)$ & $10(10-10)$ & $8(7-10)$ & $10(9-10)$ & $9.5(9-10)$ \\
\hline 2 & $10(10-10)$ & $10(8-10)$ & $10(10-10)$ & $10(10-10)$ & $7(5-9)$ & $10(9-10)$ & $8(7-9)$ \\
\hline 3 & $10(10-10)$ & $10(8-10)$ & $9.5(9-10)$ & $10(10-10)$ & $7(5-10)$ & $10(9-10)$ & $8.5(8-9)$ \\
\hline Overall & $10(10-10)$ & $10(8-10)$ & $9.8(9.7-10)$ & $10(10-10)$ & $7.3(6-8.7)$ & $10(9-10)$ & 8.7 (8.3-9) \\
\hline
\end{tabular}

Note: All videos were scored independently and in triplicate.

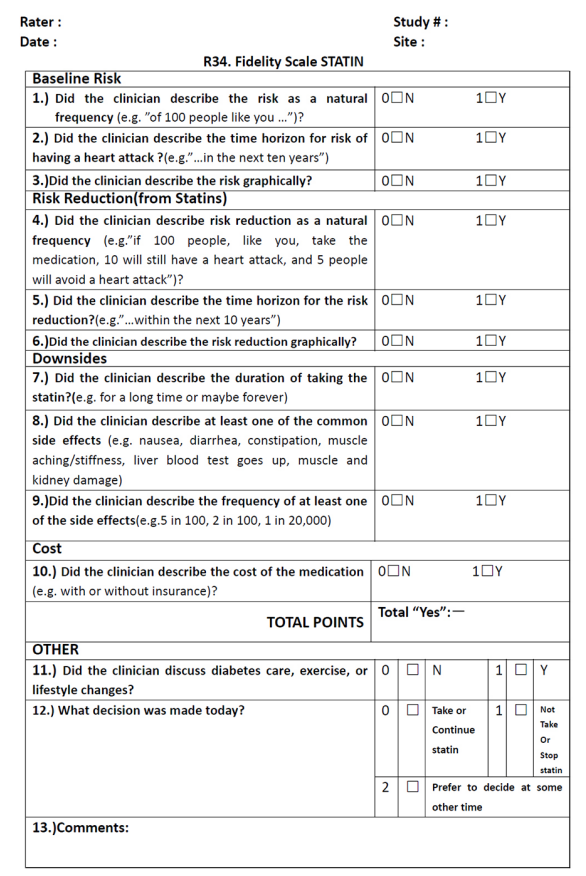

Figure SI Fidelity scale.

Patient Preference and Adherence

\section{Publish your work in this journal}

Patient Preference and Adherence is an international, peer-reviewed, open access journal that focuses on the growing importance of patient preference and adherence throughout the therapeutic continuum. Patient satisfaction, acceptability, quality of life, compliance, persistence and their role in developing new therapeutic modalities and compounds to optimize

\section{Dovepress}

clinical outcomes for existing disease states are major areas of interest for the journal. This journal has been accepted for indexing on PubMed Central. The manuscript management system is completely online and includes a very quick and fair peer-review system, which is all easy to use. Visit http://www. dovepress.com/testimonials.php to read real quotes from published authors. 